\title{
Substantiation of organizational and technological solutions for construction within the "car-free city" concept
}

\author{
Sergei Beliakov ${ }^{1, *}$ \\ ${ }^{1}$ Moscow State University of Civil Engineering, 26, Yaroslavskoye Shosse, 129337, Moscow, Russia
}

\begin{abstract}
In the article, the author developed the classification of the main models of implementation of the "car-free city" concept depending on organizational and technological solutions in the construction and reconstruction of the urban environment. The author determined that the problem of selecting the optimal model should be decided on the basis of a comprehensive analysis of various factors that determine the specific features and problems of a specific urban situation (social, technical, organizational, environmental, cultural, economic, climatic, etc). The developed solution should meet the criteria of ensuring the comfort of the urban environment and investment attractiveness. The author developed the basic algorithm of choosing the optimal organizational and technological solutions for the development of urban development within the "car-free city" concept, the use of which will contribute to maximizing socioeconomic, environmental and other effects while ensuring the investment attractiveness and competitiveness of construction project decisions.
\end{abstract}

\section{Introduction}

Steady growth in the number of private vehicles in cities causes many problems requiring the search of the optimal solution. One such problem is the need to ensure placement of vehicles the shortage of available land in Central areas of cities. It is obvious that the traditional approach to the unit Parking space by reducing the useful area of the land plots intended for construction, is not the only and best solution. [1-3]

Currently in the practice of developed countries the most promising approach to solving this problem is to improve the integrated development of territories within the "car-free city" concept. $[4,5]$

The analysis of successful projects implemented in various cities on the basis of this concept, allows us to classify models used depending on organizational and technological solutions and to identify their characteristic features.

\footnotetext{
* Corresponding author: serj-bel@yandex.ru
} 


\section{Methods}

Within the "car-free city" concept identified four main types of organizational and technological models:

- high-rise division of overpasses;

- mechanized parking space;

- eco-city;

- vertical zoning.

\subsection{The model of "high-rise division overpasses"}

This model involves the establishment of a system of pedestrian crossings that provides communication between individual buildings and eliminates the need to use personal vehicles for travel within the district. Type the location of the transitions of the model can be divided into two categories: system "skyway", involving the construction of overpasses, isolated from external climatic influences, and the system "padway", involving the creation of a network of underground tunnels. There are also examples of alignment in one area of these approaches. [6]

The model of "high-rise division overpasses" is widespread in US cities (Minneapolis, Chicago, Houston, etc.).

A key condition for the successful implementation of this model is the combination of urban objects, providing interactive functional elements within an urban area, for example, the combination of housing, educational, recreational, commercial and other areas within the education cluster.

A significant advantage of this model is to increase the comfort of the urban environment for residents of cities with severe climatic conditions.

\subsection{The model of "mechanized parking space"}

This model involves the design of specialized places of cars storage, provided various mechanisms for the delivery vehicles to the individual storage locations. The model provides significant space savings due to compact setting and the lack of internal passages. There are many different design decisions in the framework of this mode. [7]

The model of "mechanized parking space" is widespread in the major cities of Asia and Europe (Singapore, London, Moscow, etc.).

A feature of this model is the high complexity of the design, the need for control of technological processes, as well as the need to develop effective financing mechanisms.

\subsection{Model "eco-city"}

This model involves the use of innovative solutions aimed at minimizing the negative impact of urban area on the environment, as well as providing maximum energy efficiency through environmentally friendly resources. With regard to car use this concept primarily involves the refusal of vehicles in favour of environmentally friendly public transport [8].

One of the most striking examples of implementation of model "eco-city" is the city of Masdar (United Arab Emirates), which have implemented a set of solutions form a complete cycle of production of clean energy.

This model requires a comprehensive approach that goes beyond a particular district should be based on a thorough analysis of various aspects of the urban environment, is longterm implementation. 


\subsection{The model of "vertical zoning"}

This model has received to date, the most widespread, it involves the vertical zoning and the formation of individual functional elements within a multi-storey building: parking, residential, public, recreational and other zones. However, cars can be on the underground levels and the ground level [9].

Does not make sense to consider in this article the design decisions on the placement of vehicles in parking lots in the underground floors of buildings, because they are already widespread. However, in this model, there are other solutions to obtain additional social, economic and other effects due to non-standard technical solutions (for example, the project of the residential quarter "Sluseholmen" in Copenhagen, Denmark).

The features of this model are: the possibility of realization of the scale of individual buildings; the need to allocate part of the useful area of the building for parking and a corresponding reduction in the useful space of other functional areas; the need to ensure financing and technical operation of parking for the level of the owners of the building.
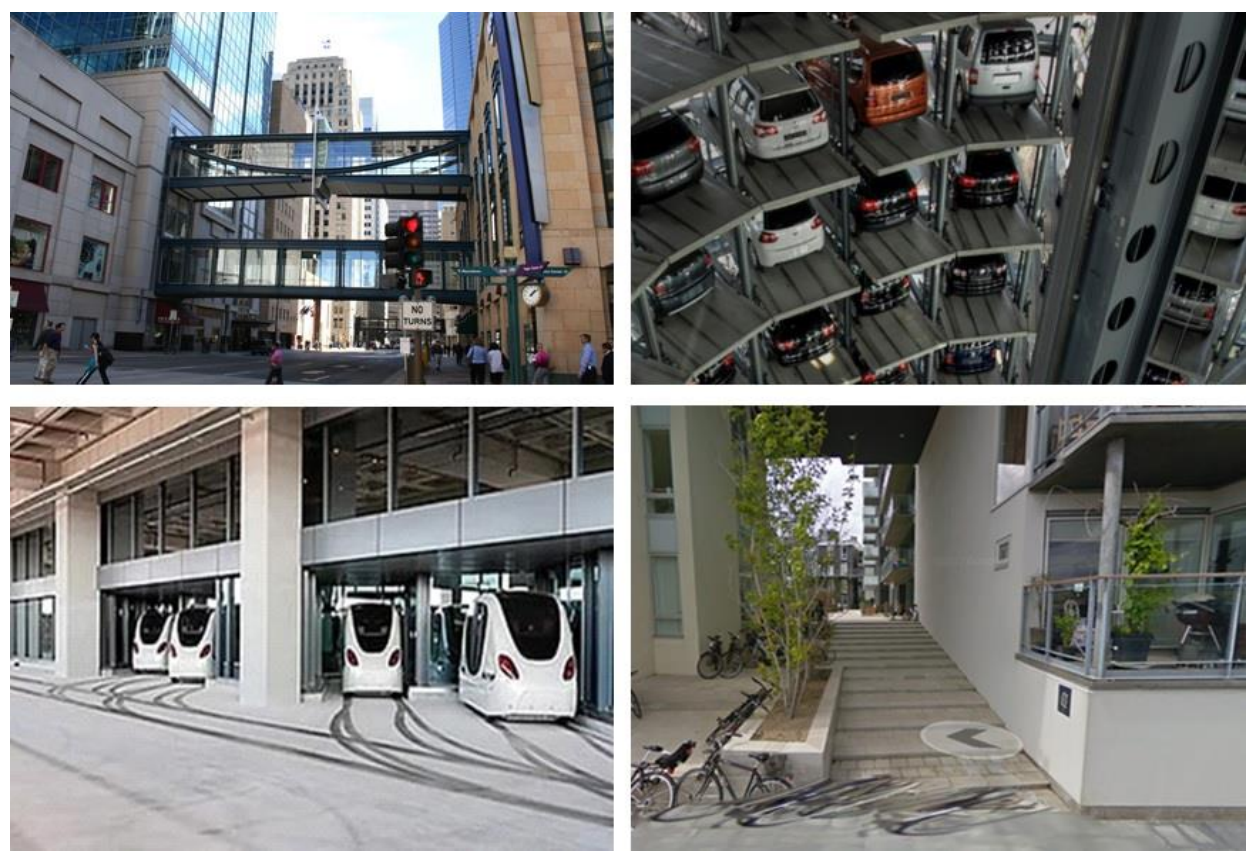

Fig. 1. Examples of implementation of the "car-free city" concept.

The problem of choosing the optimal model of implementation of the "car-free city" concept within the development of effective organizational and technological decisions on development of urban areas should be resolved on the basis of a comprehensive analysis of various factors that determine the specific features and problems of a specific urban situation (social, technical, institutional, environmental, cultural, economic, climatic, etc.), and the developed solution must meet the criteria of ensuring the comfort of the urban environment and investment attractiveness [10-13].

\section{Results and discussion}

In this article the author has elaborated the basic algorithm of substantiation of the optimal organizational and technological solutions for the development of urban territories within the "car-free city" concept (Fig. 2). 
The author simulated the processes of selection and study of optimal organizational and technological solutions for the implementation of the project, building area subject to the variant of implementation within the "car-free city" concept on the example of plot on the territory of Moscow (Russia).

This plot is intended for the construction of a public building with a restriction on the maximum number of floors - no more than 5 , is a undeveloped area of regular shape with an area of 22500 sq.m. The surrounding buildings are residential and commercial buildings with a floor from 1 to 5 .

The aim of the simulation is a comparative analysis of the indicators of construction projects implemented in accordance with the traditional approach and within the "car-free city" concept.

Since the indicators of the economic efficiency of construction projects are largely determined by the market situation in a particular area, in the framework of the simulation, the cost indicators for the implementation of the project and the usable area of the construction sites were adopted as a universal criterion for comparing the options considered $[14,15]$.

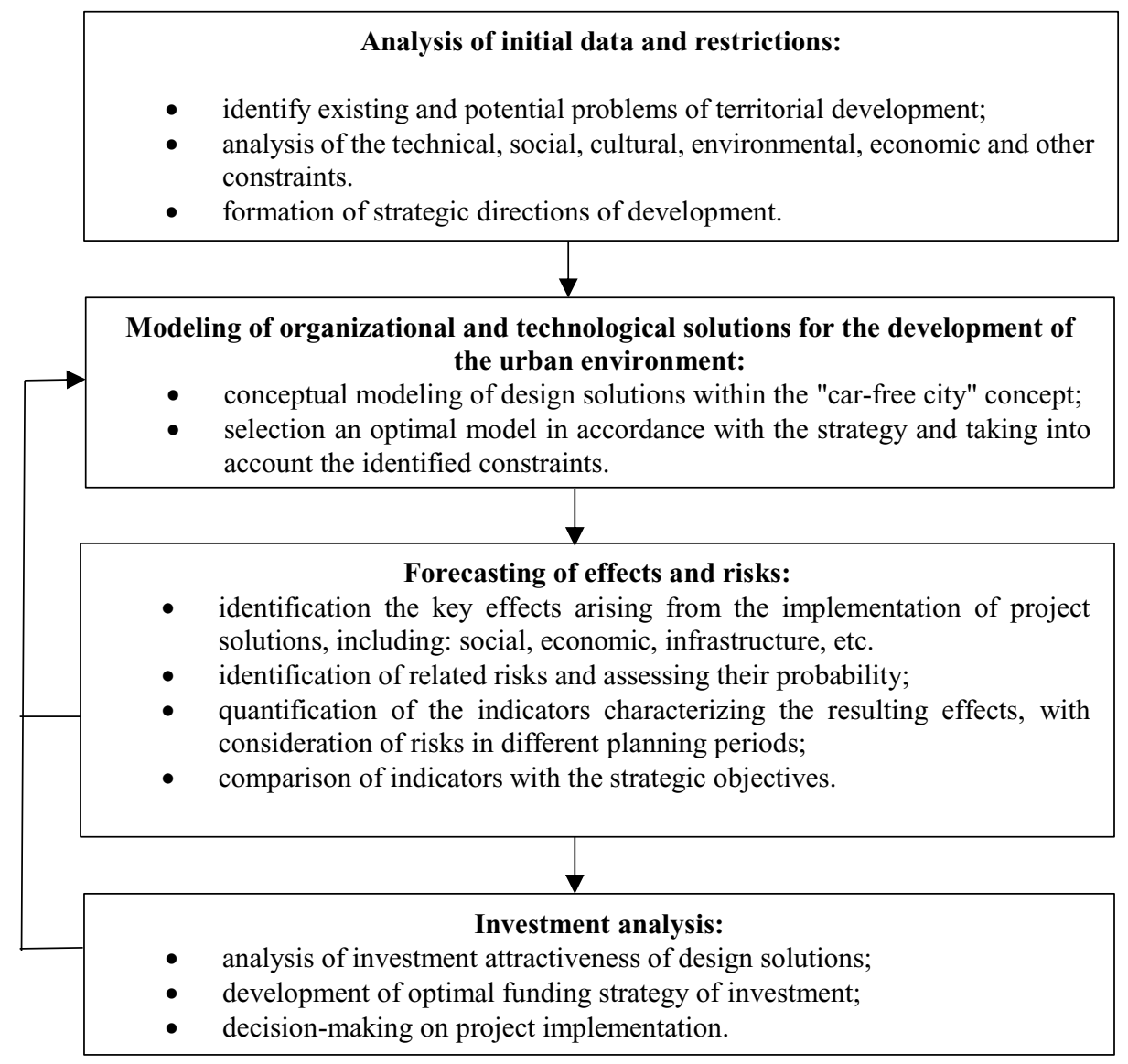

Fig. 2. The basic algorithm of substantiation of the optimal organizational and technological solutions for the development of urban territories within the "car-free city" concept.

In view of the scale of the land plot under consideration in the framework of the "car-free city" concept, it is advisable to consider the model of "vertical zoning".

Thus, in the modeling framework considered the following alternative projects (Fig. 3): 
1. Alternative project without taking into account the vertical zoning of space: the construction of public buildings up to 5 floors, the organization of Parking spaces in the adjacent territory;

2. Alternative project on the basis of a common approach within the "car-free city" concept: the construction of public buildings up to 5 floors +1 underground floor, used for parking; 3. Alternative project based on the advanced approach under the "car-free city" concept: the construction of public buildings up to 5 floors, the organization of parking on the ground floor.
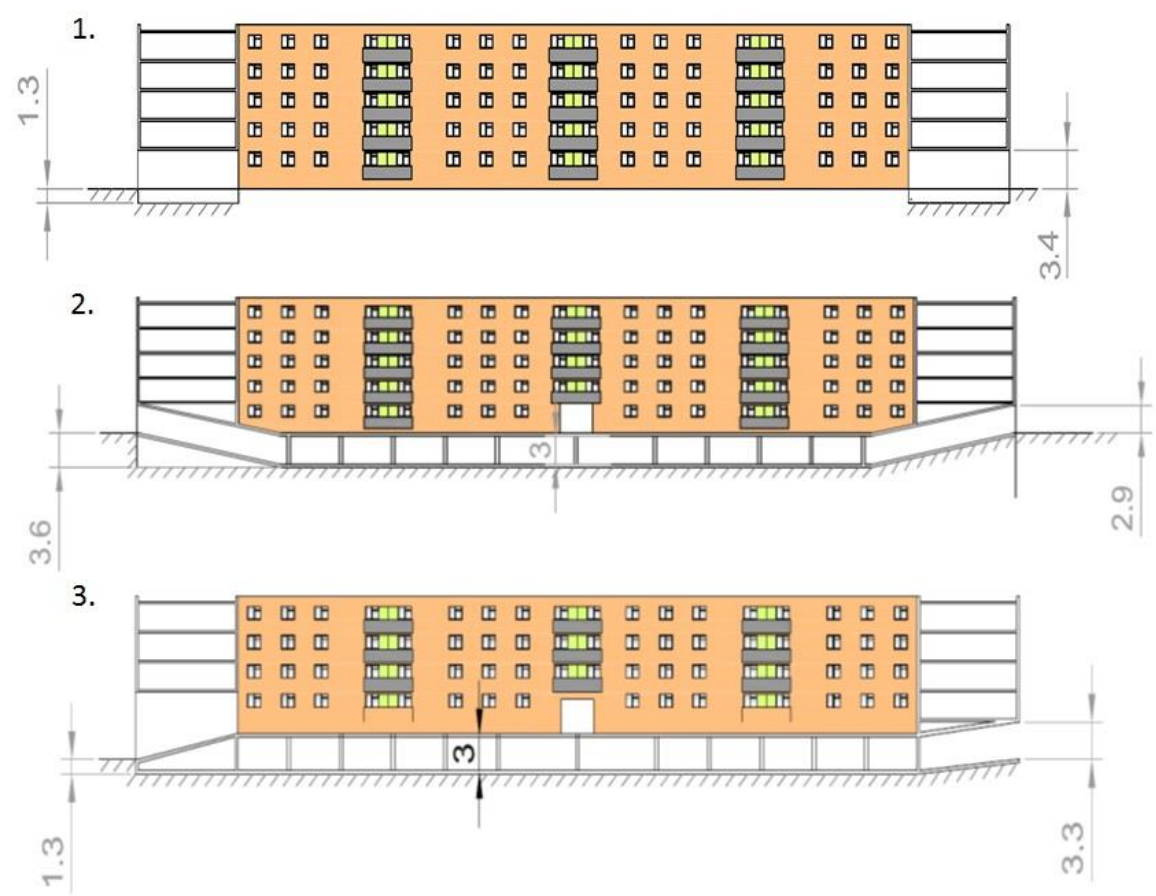

Fig. 3. A visual representation of the alternative projects.

All calculations were carried out on the basis of existing consolidated rates for the construction work, taking into account relevant regulatory requirements and recommendations. Comparative evaluation of quality indicators was carried out on the basis of expert assessments.

The results of calculations of key parameters for all the considered options are presented in the summary table (Table 1).

Table 1. Comparative results of calculation of project alternatives.

\begin{tabular}{|l|c|c|c|}
\hline \multicolumn{1}{|c|}{ Indicator } & $\begin{array}{c}\text { Alternative } \\
1\end{array}$ & $\begin{array}{c}\text { Alternative } \\
2\end{array}$ & $\begin{array}{c}\text { Alternative } \\
3\end{array}$ \\
\hline $\begin{array}{l}\text { The cost of construction of the underground } \\
\text { part, RUB }\end{array}$ & 68224295 & $\begin{array}{c}131293 \\
200\end{array}$ & $\begin{array}{c}117972 \\
900\end{array}$ \\
\hline The number of parking spaces & 126 & 126 & 126 \\
\hline Useful area public buildings, sq. m. & 19045 & 37170 & 29080 \\
\hline The improvement area, sq. m. & 3700 & 14145 & 17230 \\
\hline $\begin{array}{l}\text { The duration of design and construction, } \\
\text { months }\end{array}$ & 15 & 22 & 18 \\
\hline $\begin{array}{l}\text { Architectural and aesthetic conformity with the } \\
\text { environment }\end{array}$ & + & +++ & +++ \\
\hline
\end{tabular}




\begin{tabular}{|l|c|c|c|}
\hline Ecological compatibility & + & ++ & +++ \\
\hline The comfort level of environment & + & +++ & +++ \\
\hline
\end{tabular}

\section{Conclusions}

Obtained during the modeling results show that, in terms of the ratio of the useful area of the object and the magnitude of the implementation costs of the project, all alternatives have approximately equal performance. However, other indicators that are crucial in meeting the challenges of sustainable urban development, the most preferred alternative projects are developed based on the "car-free city" concept, in particular the alternative 3 (developed based an improved model of "vertical zoning").

The obtained results allow to conclude about the reasonable of applying the "car-free city" concept in developing of construction projects in the framework of the general strategy for sustainable urban development of major cities. Application of the developed algorithm of substantiation the optimal organizational and technological solutions on the basis of the "carfree city" concept will contribute to maximizing socio-economic, environmental and other effects while ensuring the investment attractiveness and competitiveness of construction project decisions.

\section{References}

1. M.V. Boykova, I.N. Ilyina, M.G. Salazkin, Forsyth Magazine, 4 (2011)

2. A.A. Baranov, Academic Bulletin UralNIIproekt RAASN, 3 (2009)

3. S.G. Sheina, E.N. Minenko, Real estate: economics, management, 2 (2015)

4. J.M. Nieuwenhuijsen, H. Khreis, Environment International, 94 (2016)

5. A.E. Brown, Transport Policy, 60 (2017)

6. N. Quang Minh, Procedia Engineering, 142 (2016)

7. H.Khreis, M. Nieuwenhuijsen, J. Bastiaanssen, Journal of Transport \& Health, 5 (2017)

8. M. Ornetzeder, E. G. Hertwich, K. Hubacek, K. Korytarova, W. Haas, Ecological Economics, 65(3) (2008)

9. A.Yu. Reteyum, Architecture and construction of Russia, 8 (2014)

10. R.R. Kazaryan, V.O. Chulkov, Organizational and technological innovations of housing and communal and investment-building complexes in the development of the city: International collection of scientific papers (MGAKHiS, Moscow,2 012)

11. G.M. Solodikhin, I.K. Yazhlev, Volga scientific journal, 3 (31) (2014)

12. V. Rybchinsky, City designer: Ideas and cities (Strelka Press, Moscow, 2014)

13. B. Hillier, The Fourth Sustainability, Creativity: Statistical Associations and Credible Mechanisms. Complexity, Cognition, Urban Planning and Design (2016)

14. S.V. Ilinova, Increase of economic efficiency of ecological safety of transport system, the Engineering bulletin of Don Transport (2010)

15. L. Girya, S. Sheina, P. Fedyaeva, Journal of Applied Engineering Research, 8 (2015) 